\title{
Enhanced Supercapacitance of Hydrous Ruthenium Oxide/Mesocarbon Microbeads Composites toward Electrochemical Capacitors
}

\author{
Changzhou Yuan, Linrui Hou, Diankai Li, Long Yang, and Jiaoyang Li \\ Anhui Key Laboratory of Metal Materials \& Processing, School of Materials Science \& Engineering, \\ Anhui University of Technology, Ma'anshan 243002, China \\ Correspondence should be addressed to Changzhou Yuan, ayuancz@163.com
}

Received 25 November 2011; Accepted 2 January 2012

Academic Editor: Rubin Gulaboski

Copyright ( $\odot 2012$ Changzhou Yuan et al. This is an open access article distributed under the Creative Commons Attribution License, which permits unrestricted use, distribution, and reproduction in any medium, provided the original work is properly cited.

A facile hydrothermal strategy was proposed to synthesize $\mathrm{RuO}_{2} \cdot n \mathrm{H}_{2} \mathrm{O} /$ mesocarbon microbeads (MCMBs) composites. Further physical characterizations revealed that $\mathrm{RuO}_{2} \cdot n \mathrm{H}_{2} \mathrm{O}$ nanoparticles (NPs) were well dispersed upon the surfaces of the MCMB pretreated in $6 \mathrm{M} \mathrm{KOH}$ solution. Electrochemical data indicated that the $\mathrm{RuO}_{2} \cdot n \mathrm{H}_{2} \mathrm{O} / \mathrm{MCMB}$ composites owned higher electrochemical utilization of $\mathrm{RuO}_{2}$ species, better power property, and better electrochemical stability, compared with the single $\mathrm{RuO}_{2}$ phase. The good dispersion of $\mathrm{RuO}_{2} \cdot n \mathrm{H}_{2} \mathrm{O}$ NPs and enhanced electronic conductivity made the $\mathrm{H}^{+}$ions and electrons easily contact the $\mathrm{RuO}_{2} \cdot n \mathrm{H}_{2} \mathrm{O}$ phase for efficient energy storage at high rates.

\section{Introduction}

Electrochemical capacitors (ECs) are a kind of charge-storage devices possessing higher power density, more excellent reversibility, longer life cycle than batteries and much higher energy density compared to conventional capacitors [1]. Owing to these extraordinary properties, ECs have attracted increased interests during the past years with projected applications in the hybrid vehicle systems and memory backup systems. The electrochemical performance of ECs depends upon the electroactive materials greatly. Among these electroactive materials, hydrous ruthenium oxide $\left(\mathrm{RuO}_{2} \cdot n \mathrm{H}_{2} \mathrm{O}\right)$ has been recognized as the state-of-the-art electrode material, due to its facile transport pathways for both protons and electrons, high specific capacitance (SC), highly reversible redox reactions, and so forth, [2-8]. However, a very high cost and toxic nature greatly preclude its commercial application. For this reason, the approaches to reduce its amount and further enhance its electrochemical utilization are essential to make the $\mathrm{RuO}_{2}$-based devices more cost-effective.

It is well established that the good dispersion of $\mathrm{RuO}_{2}$. $n \mathrm{H}_{2} \mathrm{O}$ nanoparticles (NPs) upon the surface of the carbon matrices is much favorable for enhancing their electrochemical utilization [4-8]. And the $\mathrm{RuO}_{2} \cdot n \mathrm{H}_{2} \mathrm{O}$ /carbonbased composites delivered a wide SC range from 150 to $1580 \mathrm{Fg}^{-1}[5,8]$, which was greatly depending upon the loading and thickness of the $\mathrm{RuO}_{2} \cdot n \mathrm{H}_{2} \mathrm{O}$ existing in the carbon materials. Commonly, the used carbon materials include carbon nanotubes [4], activated carbon [5], carbon black [6], and carbon nanofibres [7]. Since mesocarbon microbeads (MCMB) were first separated by Honda and Yamada from the mesophase pitches [9], this typical carbon material has been used in many applications, such as high-density carbon material $[10,11]$, filler for high-performance liquid chromatography [12], active carbon with super high surface [13], anodes of lithium ion battery [14-18], alkaline zinc-air cells [19], and supports of NiO NPs for ECs [20].

To the best of our knowledge, the investigation of the MCMB as a support to disperse $\mathrm{RuO}_{2} \cdot n \mathrm{H}_{2} \mathrm{O}$ NPs for ECs has not been reported as yet. In this work, the $\mathrm{RuO}_{2} \cdot n \mathrm{H}_{2} \mathrm{O}$ NPs were well dispersed upon the surfaces of the MCMB via mild hydrothermal method. Such unique $\mathrm{RuO}_{2} \cdot n \mathrm{H}_{2} \mathrm{O}$ / MCMB composites can not only enhance the dispersion of $\mathrm{RuO}_{2} \cdot n \mathrm{H}_{2} \mathrm{O}$ NPs but remit their serious aggregation 
meanwhile. Furthermore, the micrometer size of $\mathrm{RuO}_{2}$. $n \mathrm{H}_{2} \mathrm{O} / \mathrm{MCMB}$ composites greatly favors for their practical fabrication. Electrochemical performance of the $\mathrm{RuO}_{2}$. $n \mathrm{H}_{2} \mathrm{O} / \mathrm{MCMB}$ composites was systematically investigated in $0.5 \mathrm{M} \mathrm{H}_{2} \mathrm{SO}_{4}$ aqueous solution. Electrochemical data indicated that the $\mathrm{RuO}_{2} \cdot n \mathrm{H}_{2} \mathrm{O} / \mathrm{MCMB}$ composites owned higher electrochemical utilization, better power property, and better electrochemical stability, in contrast to the single $\mathrm{RuO}_{2}$ phase.

\section{Experimental}

2.1. Synthesis of the $\mathrm{RuO}_{2} \cdot n \mathrm{H}_{2} \mathrm{O} / \mathrm{MCMB}$ Composites. Herein, the MCMB was provided by Shanshan Science and Technology Corporation (Shanghai). Its specific surface area (SSA) is ca. $4 \mathrm{~m}^{2} \mathrm{~g}^{-1}$ and its particle size distribution (PSD) ranged from 1 to $3 \mu \mathrm{m}$. The purchased MCMB was further under hydrothermal pretreatment in $6 \mathrm{M} \mathrm{KOH}$ solution at $150^{\circ} \mathrm{C}$ for $8 \mathrm{~h}$ and then washed with distilled water until the pH reached 8 [20]. The $\mathrm{RuO}_{2} \cdot n \mathrm{H}_{2} \mathrm{O} / \mathrm{MCMB}$ composites were fabricated as follows. Firstly, a certain amount of $\mathrm{RuCl}_{3}$. $n \mathrm{H}_{2} \mathrm{O}$ was dissolved in some distilled water under stirring for $1 \mathrm{~h}$ to form a solution $(0.018 \mathrm{M})$. Secondly, some certain amount of the pretreated MCMB was mixed into the above solution under stirring for $1 \mathrm{~h}$ and further ultrasonication for half an hour to form a suspension. And then the suspension was kept in a Teflon-lined autoclave with a stainless steel shell. After being kept at $180^{\circ} \mathrm{C}$ for $6 \mathrm{~h}$ in an oven [3], this autoclave was cooled to room temperature naturally. The product of the reaction was filtered, washed with distilled water and ethanol, and then dried at $80^{\circ} \mathrm{C}$. The composition of the $\mathrm{RuO}_{2} \cdot n \mathrm{H}_{2} \mathrm{O} / \mathrm{MCMB}$ composites was controlled by changing the relative ratio of $\mathrm{RuCl}_{3} \cdot n \mathrm{H}_{2} \mathrm{O}$ and MCMB support in the starting mixture. The morphologies of the samples were examined by field-emission scanning electron microscope (FESEM, JEOL-6300F). The X-ray diffraction patterns of the samples were observed by XRD (Max 18 XCE Japan) using a $\mathrm{Cu}_{\mathrm{Ka}}$ source.

2.2. Electrochemical Tests. The graphite electrode was first abraded with ultrafine $\mathrm{SiC}$ paper, rinsed in an ultrasonic bath of water for 10 minutes, and etched in a $0.5 \mathrm{M} \mathrm{H}_{2} \mathrm{SO}_{4}$ solution at room temperature for 40 minutes. The exposed geometric area of the graphite electrode is equal to $1 \mathrm{~cm}^{2}$. Electrodes were prepared by mixing the active materials with acetylene black (AB) and polytetrafluoroethylene (PTFE) with the weight ratio of $10: 1.5: 0.5$. A small amount of $0.5 \mathrm{M} \mathrm{H}_{2} \mathrm{SO}_{4}$ solution was then added to this composite to form a more homogeneous and coating slurry. This slurry was smeared onto the pretreated graphite substrate and then dried in a vacuum oven at $50^{\circ} \mathrm{C}$ overnight.

A beaker-type electrochemical cell was used for the electrochemical measurement. The cell was equipped with a working electrode, a platinum plate counter electrode, and saturated calomel electrode (SCE) reference electrode. All electrochemical measurements were done in a three-electrode system with $0.5 \mathrm{M} \mathrm{H}_{2} \mathrm{SO}_{4}$ solution. And all potential values in the present study are reported against the SCE. Cyclic voltammetry (CV) was evaluated by using CHI660C electrochemical workstation. Electrochemical impedance spectroscopy (EIS) was performed with a frequency response analyzer (Solatron 1255B) interfaced with potential galvanostat (Solatron 1287) controlled by a personal computer. Chronopotentiometry (CP) curves of the electrodes were evaluated with an Arbin BT2042 battery workstation system in the certain potential ranges.

\section{Results and Discussion}

3.1. Characterization of the $\mathrm{RuO}_{2} \cdot n \mathrm{H}_{2} \mathrm{O} / \mathrm{MCMB}$ Composites. XRD patterns of the as-synthesized $\mathrm{RuO}_{2} \cdot n \mathrm{H}_{2} \mathrm{O} / \mathrm{MCMB}$ composites with different loadings are presented in Figure 1 as indicated. As shown in Figure 1(a), the peak intensity of the MCMB at $2 \theta=26.5^{\circ}$ dramatically diminishes after loading $\mathrm{RuO}_{2} \cdot n \mathrm{H}_{2} \mathrm{O}$ NPs. Moreover, with the increase of $\mathrm{RuO}_{2} \cdot n \mathrm{H}_{2} \mathrm{O}$ NPs loadings, the peak intensity of the MCMB at $2 \theta=26.5^{\circ}$ decreases more and more. Notably, the peak intensities of the $\mathrm{MCMB}$ from $40^{\circ}$ to $60^{\circ}$ also decrease greatly after loading $\mathrm{RuO}_{2} \cdot n \mathrm{H}_{2} \mathrm{O}$ NPs and keep the same decreasing trend as the peak at $2 \theta=26.5^{\circ}$, as depicted in Figure $1(\mathrm{~b})$. All these data support that the MCMB has been successfully coated with $\mathrm{RuO}_{2} \cdot n \mathrm{H}_{2} \mathrm{O}$ NPs after hydrothermal treatment. However, the obvious diffraction peaks of the $\mathrm{RuO}_{2} \cdot n \mathrm{H}_{2} \mathrm{O}$ phase cannot be found in Figures $1(\mathrm{a})$ and 1(b). Thus, the typical XRD pattern of $\mathrm{RuO}_{2} \cdot n \mathrm{H}_{2} \mathrm{O} / \mathrm{MCMB}$ composite with 100 wt. $\% \mathrm{RuO}_{2} \cdot n \mathrm{H}_{2} \mathrm{O}$ NPs, that is, the pure $\mathrm{RuO}_{2} \cdot n \mathrm{H}_{2} \mathrm{O}$ phase, is further shown in Figure 1(b). In sharp contrast, the broad diffraction peaks with very low intensity are presented for the $\mathrm{RuO}_{2} \cdot n \mathrm{H}_{2} \mathrm{O}$ phase. And these typical diffraction peaks should result from the relative poor crystalline quality and/or nanometer-scale size of the as-prepared hydrous $\mathrm{RuO}_{2}$ NPs. To more clearly identify the existence of $\mathrm{RuO}_{2}$ phase in the composites, the enlarged XRD patterns of the pure $\mathrm{RuO}_{2} \cdot n \mathrm{H}_{2} \mathrm{O}$ and $\mathrm{RuO}_{2} \cdot n \mathrm{H}_{2} \mathrm{O} / \mathrm{MCMB}$ composite with 12.5 wt. $\% \mathrm{RuO}_{2} \cdot n \mathrm{H}_{2} \mathrm{O}$ NPs were shown in Figure 1(c), respectively. Evidently, four obvious broad diffraction peaks contributed by the rutile $\mathrm{RuO}_{2}$ phase (JCPDS card no. 431027) can be found both in the two samples, which indicates the real existence $\mathrm{RuO}_{2} \cdot n \mathrm{H}_{2} \mathrm{O}$ in the $\mathrm{RuO}_{2} \cdot n \mathrm{H}_{2} \mathrm{O} / \mathrm{MCMB}$ composites.

The FESEM images of the $\mathrm{RuO}_{2} \cdot n \mathrm{H}_{2} \mathrm{O} / \mathrm{MCMB}$ composite with the 24.8 wt. $\% \mathrm{RuO}_{2} \cdot n \mathrm{H}_{2} \mathrm{O}$ NPs are shown in Figure 2. Evidently, the $\mathrm{RuO}_{2} \cdot n \mathrm{H}_{2} \mathrm{O} / \mathrm{MCMB}$ composite exhibits uniform spherical grains with the size of $1 \sim 2 \mu \mathrm{m}$, as shown in Figure 2(a). From the image with the higher magnification (Figure 2(b)), the nanosized $\mathrm{RuO}_{2} \cdot n \mathrm{H}_{2} \mathrm{O}$ NPs are evidently dispersed well onto the surfaces of the MCMB, the reasons for which are mainly related to the unique surface characteristics of the MCMB after the alkaline hydrothermal pretreatment. As reported before, substantial amounts of $\mathrm{OH}^{-}$would exist upon the surfaces of the MCMB after such pretreatment [20]. The $\mathrm{OH}^{-}$existing upon the surfaces of the MCMB not only improves the surface hydrophilic property of the MCMB but also acts as anchors for the subsequent deposition of $\mathrm{RuO}_{2} \cdot n \mathrm{H}_{2} \mathrm{O}$ NPs upon their surfaces [20]. Specifically, during stirring the suspension of the MCMB in the solution with $\mathrm{Ru}^{3+}$ ions, some precipitation would form onto the surfaces of the MCMB. Thus, 


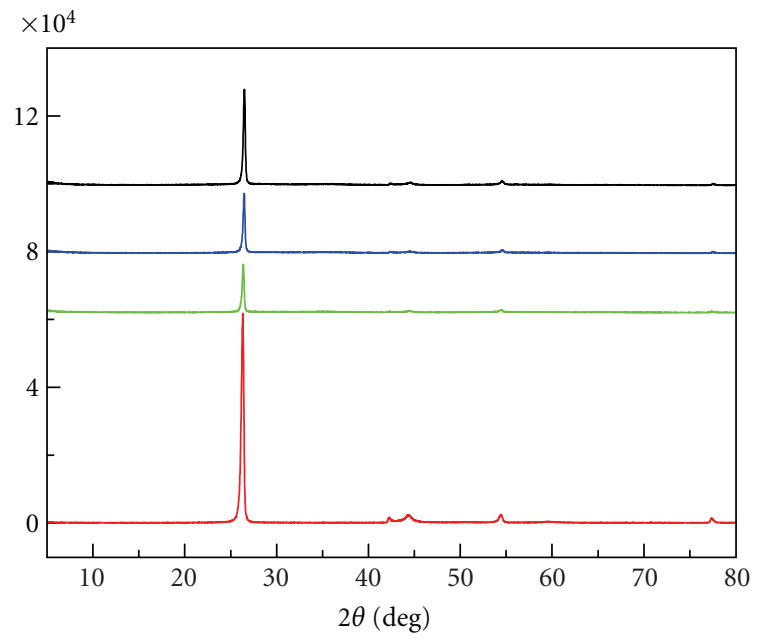

(a)

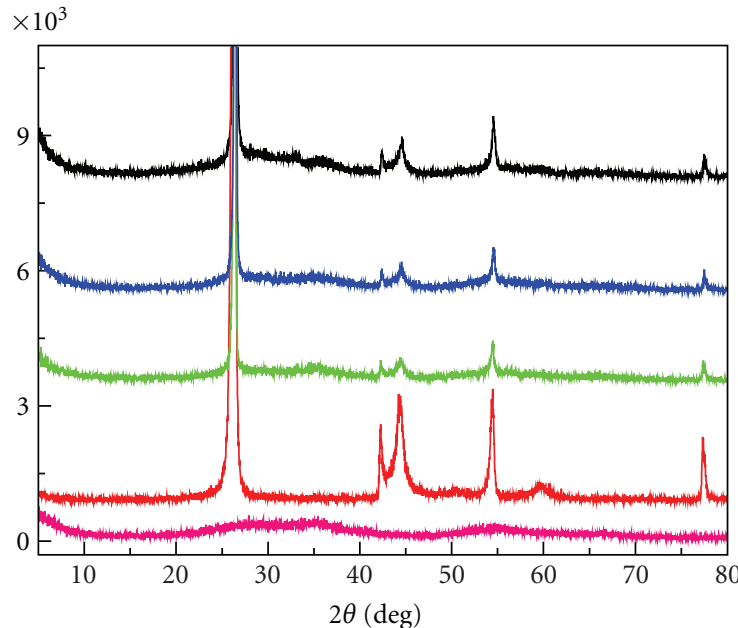

(b)

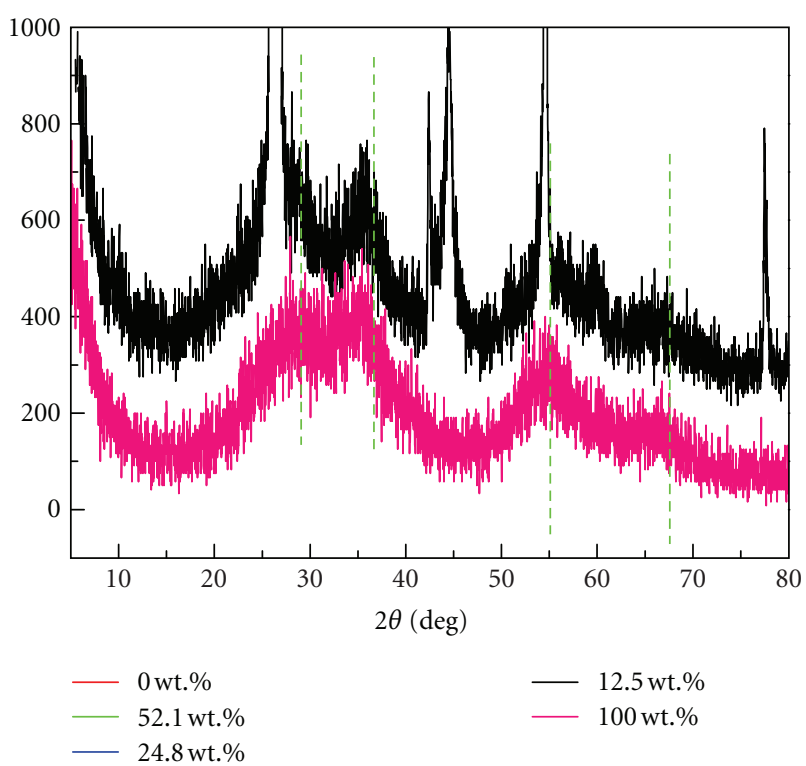

(c)

FIgURE 1: XRD patterns of $\mathrm{RuO}_{2} \cdot n \mathrm{H}_{2} \mathrm{O} / \mathrm{MCMB}$ composites with different $\mathrm{RuO}_{2} \cdot n \mathrm{H}_{2} \mathrm{O}$ loadings as indicated.

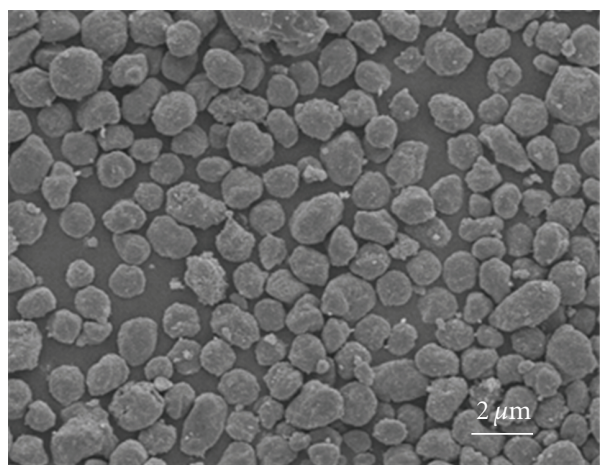

(a)

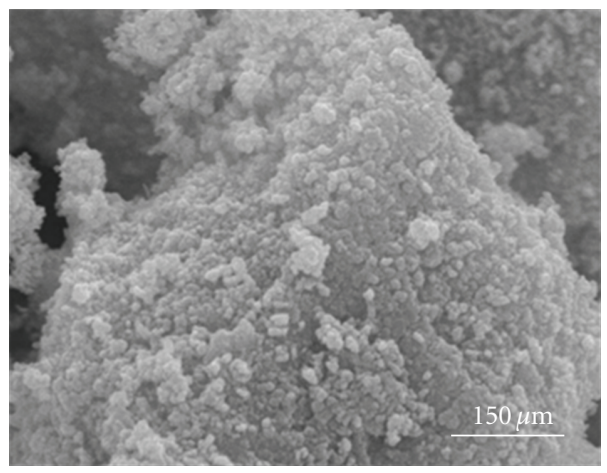

(b)

Figure 2: SEM images with different magnifications for the $\mathrm{RuO}_{2} \cdot n \mathrm{H}_{2} \mathrm{O} / \mathrm{MCMB}$ composite with 24.8 wt. $\% \mathrm{RuO}_{2} \cdot n \mathrm{H}_{2} \mathrm{O} \mathrm{NPs}_{\text {. }}$ 


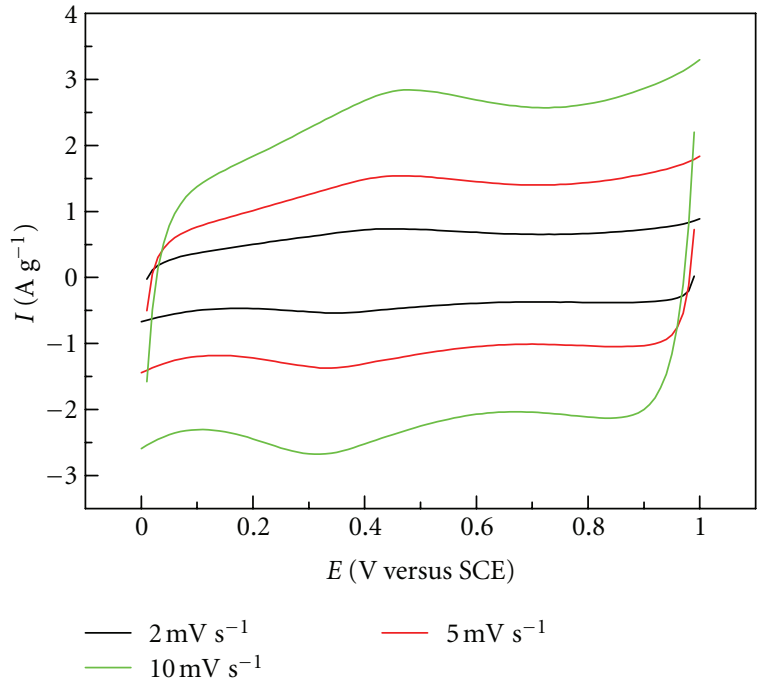

(a)

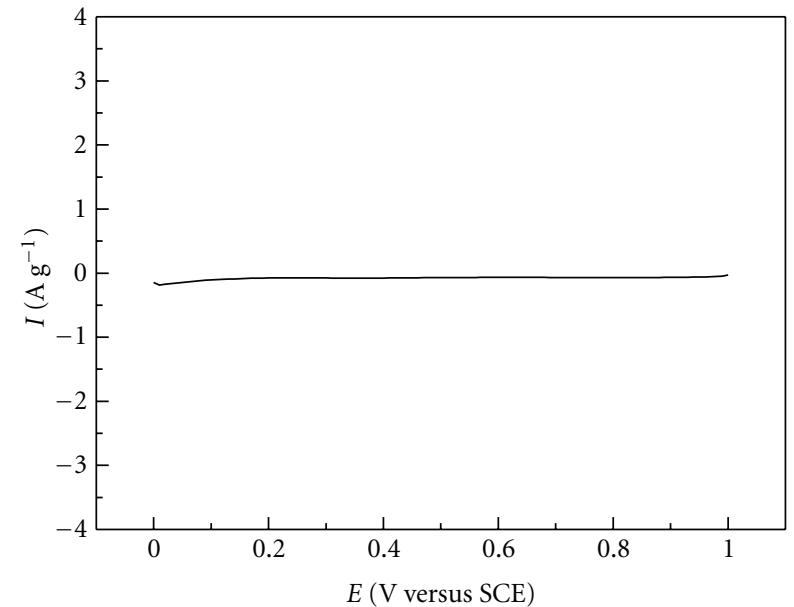

(b)

FIgURE 3: E-I curves of the $\mathrm{RuO}_{2} \cdot n \mathrm{H}_{2} \mathrm{O} / \mathrm{MCMB}$ composite electrode with 24.8 wt. $\% \mathrm{RuO}_{2} \cdot n \mathrm{H}_{2} \mathrm{O}$ NPs at various scanning rates as indicated (a) and the MCMB at $10 \mathrm{mV} \mathrm{s}^{-1}$.

with the following hydrothermal treatment at $180^{\circ} \mathrm{C}$, initial precipitation can act as nucleation centers, which results in more and more $\mathrm{RuO}_{2} \cdot n \mathrm{H}_{2} \mathrm{O}$ NPs coating onto the surfaces of the MCMB after hydrothermal treatment. Therefore, the alkaline hydrothermal treatment of MCMB plays a great role in the formation of $\mathrm{RuO}_{2} \cdot n \mathrm{H}_{2} \mathrm{O} / \mathrm{MCMB}$ composites with good dispersion of $\mathrm{RuO}_{2} \cdot n \mathrm{H}_{2} \mathrm{O}$ NPs.

3.2. Electrochemical Profiles of the $\mathrm{RuO}_{2} \cdot n \mathrm{H}_{2} \mathrm{O} / \mathrm{MCMB} \mathrm{Com}$ posites. Cyclic voltammetry was used to determine the electrochemical properties of the $\mathrm{RuO}_{2} \cdot n \mathrm{H}_{2} \mathrm{O} / \mathrm{MCMB}$ composites. Figure 3(a) shows the CV plots of the $\mathrm{RuO}_{2} \cdot n \mathrm{H}_{2} \mathrm{O}$ / MCMB composite with 24.8 wt. $\% \mathrm{RuO}_{2} \cdot n \mathrm{H}_{2} \mathrm{O}$ NPs in $0.5 \mathrm{M}$ $\mathrm{H}_{2} \mathrm{SO}_{4}$ aqueous solution. Obviously, the CV curves of the composite all display a good rectangular shape with respect to the zero-current line and a repaid current response on voltage reversal at each end potential at various scanning rates as indicated. Also, the E-I response of the composite on the positive sweep is mirror-image symmetric to their corresponding counterpart on the negative sweep within the electrochemical window from 0.0 to $1.0 \mathrm{~V}$ (versus SCE), revealing a good electrochemical capacitive nature for the composite electrode in $0.5 \mathrm{M} \mathrm{H}_{2} \mathrm{SO}_{4}$. For comparison, the E-I response of the MCMB is also depicted in Figure 3(b). Evidently, the area under the current potential is extremely small even at $10 \mathrm{mV} \mathrm{s}^{-1}$. It reveals that the SC of the MCMB is very little and nearly equal to zero, which should result from the low SSA of the MCMB itself. Therefore, the main phase in the composite for energy storage should be the $\mathrm{RuO}_{2} \cdot n \mathrm{H}_{2} \mathrm{O}$ NPs, rather than the MCMB phase. The typical Faradaic pseudocapacitance of the $\mathrm{RuO}_{2} \cdot n \mathrm{H}_{2} \mathrm{O}$ is demonstrated in

$$
\mathrm{RuO}_{a}(\mathrm{OH})_{b}+\delta \mathrm{H}^{+}+\delta \mathrm{e}^{-}=\mathrm{RuO}_{a-\delta}(\mathrm{OH})_{b+\delta} .
$$

The charge-discharge study under various applied constant current densities is commonly used to examine the SC, electrochemical reversibility, and power property of any electrode material. Thus, typical CP curves of the $\mathrm{RuO}_{2}$. $n \mathrm{H}_{2} \mathrm{O} / \mathrm{MCMB}$ composite (24.8 wt.\% $\mathrm{RuO}_{2} \cdot n \mathrm{H}_{2} \mathrm{O}$ NPs) at various current densities are shown in Figure 4(a). The E- $t$ responses present a symmetric triangular shape, and the potential is linearly dependent on the charge-discharge time, which exhibits its good supercapacitive behavior. An important parameter, columbic efficiency $(\eta)$ of the composite electrode, can be evaluated from (2) based on the CP plots depicted in Figure 4(a):

$$
\eta=\frac{t_{\mathrm{D}}}{t_{\mathrm{C}}} \times 100 \%
$$

where $t_{\mathrm{D}}$ and $t_{\mathrm{C}}$ are the time for galvanostatic discharging and charging, respectively. The columbic efficiencies at different current densities ranged from 0.5 to $5 \mathrm{Ag}^{-1}$ all keep above $99.4 \%$, revealing its good electrochemical reversibility.

Furthermore, the SCs of the composite electrode were calculated from the CP curves (Figure 4(a)) based on (3) and the typical data are depicted in Figure 4(b):

$$
\begin{gathered}
\mathrm{SC}_{\text {composite }}=\frac{I t}{\Delta V}, \\
\mathrm{SC}_{\mathrm{Ru}}=\frac{\mathrm{SC}_{\text {composite }}}{w},
\end{gathered}
$$

where $\mathrm{SC}_{\text {composite }}, \mathrm{SC}_{\mathrm{Ru}}, I, t, \Delta V$, and $w$ are the $\mathrm{SC}\left(\mathrm{Fg}^{-1}\right)$ of the composite electrode, the SC $\left(\mathrm{Fg}^{-1}\right)$ contributed by the single $\mathrm{RuO}_{2} \cdot n \mathrm{H}_{2} \mathrm{O}$ species, the charge/discharge current density $\left(\mathrm{Ag}^{-1}\right)$, the time (s) elapsed for the discharge cycles, the potential interval $(\mathrm{V})$ of the discharge, and the percentage of $\mathrm{RuO}_{2} \cdot n \mathrm{H}_{2} \mathrm{O}$ existing in the composites, respectively.

The SCs contributed by the $\mathrm{RuO}_{2} \cdot n \mathrm{H}_{2} \mathrm{O}$ species as a function of current densities are shown in Figure 4(b). Impressively, a $\mathrm{SC}_{\mathrm{Ru}}$ of $1084 \mathrm{Fg}^{-1}$ can be delivered at a current density of $0.5 \mathrm{Ag}^{-1}$ by the composite electrode with 


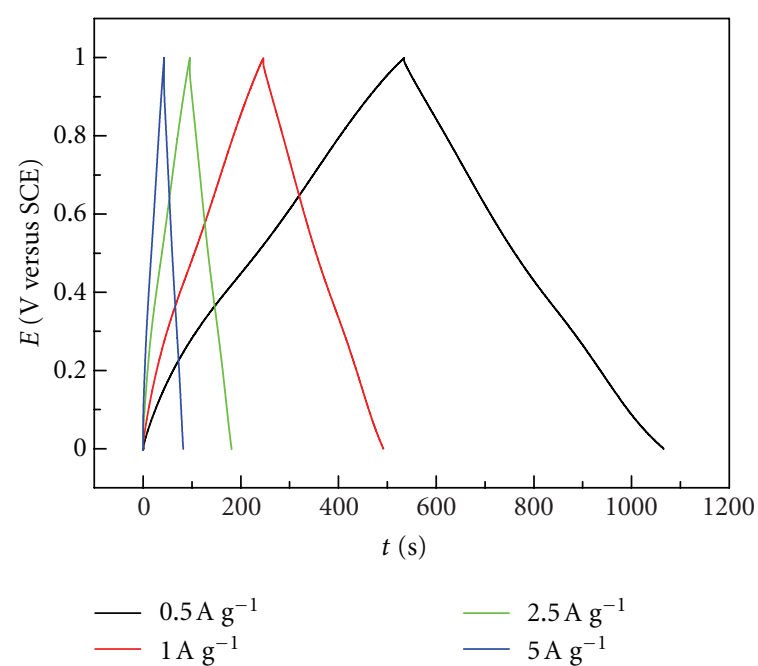

(a)

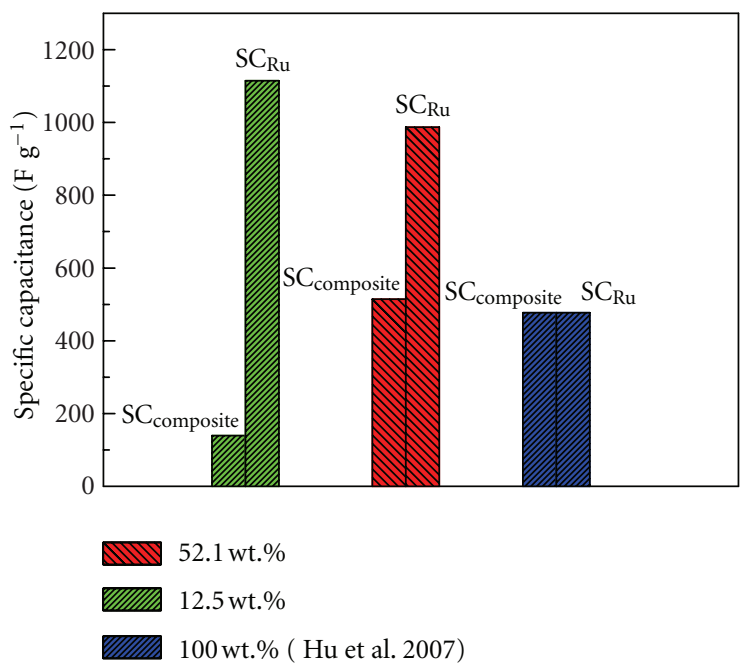

(c)

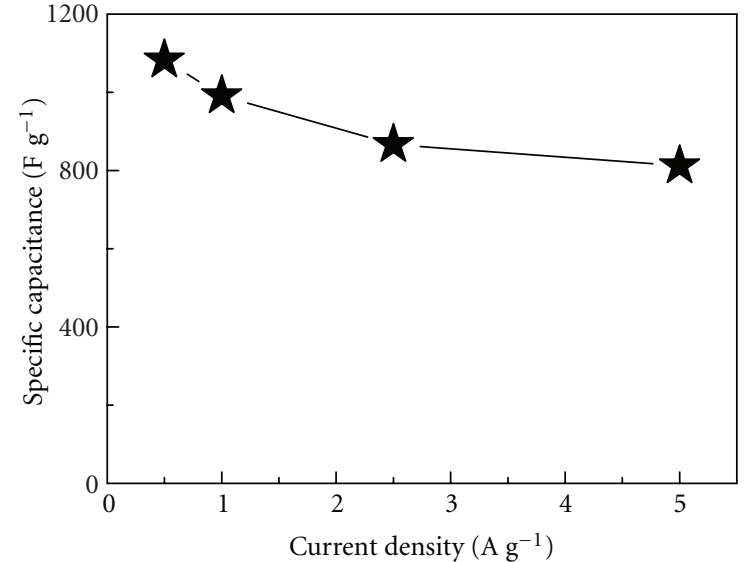

(b)

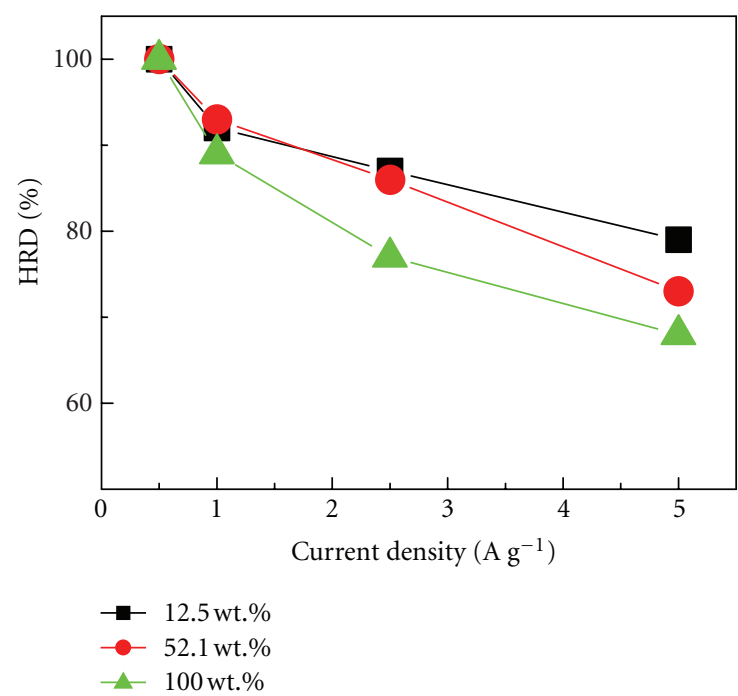

(d)

Figure 4: CP plots (a) and $\mathrm{SC}_{\mathrm{Ru}}$ as a function of current densities (b) of the $\mathrm{RuO}_{2} \cdot n \mathrm{H}_{2} \mathrm{O} / \mathrm{MCMB}$ composite with 24.8 wt. $\%$ RuO ${ }_{2} \cdot n \mathrm{H}_{2} \mathrm{O}$; specific capacitances (c) and HRD curves (d) of the $\mathrm{RuO}_{2} \cdot n \mathrm{H}_{2} \mathrm{O} / \mathrm{MCMB}$ composites with 12.5 wt. $\%, 52.1$ wt. $\%$ and 100 wt. $\% \mathrm{RuO}_{2} \cdot n \mathrm{H}_{2} \mathrm{O}$ NPs, respectively.

24.8 wt. $\% \mathrm{RuO}_{2} \cdot n \mathrm{H}_{2} \mathrm{O}$ NPs. Furthermore, the electrode not only exhibit high SCs but also maintain them well at much higher current densities. Specifically, the electrode preserves more than $74 \%$ of its SC delivered at $0.5 \mathrm{~A} / \mathrm{g}$ as the current density increases to $5 \mathrm{~A} \mathrm{~g}^{-1}$, that is, even $812 \mathrm{~F} \mathrm{~g}^{-1}$ at $5 \mathrm{Ag}^{-1}$. For other composites with different $\mathrm{RuO}_{2} \cdot n \mathrm{H}_{2} \mathrm{O}$ loadings, the $\mathrm{SC}_{\text {composite }}$ and $\mathrm{SC}_{\mathrm{Ru}}$ were also estimated and collected in Figure 4(c). As reported before [3], the $\mathrm{SC}_{\mathrm{Ru}}$ of the bare $\mathrm{RuO}_{2} \cdot n \mathrm{H}_{2} \mathrm{O}$, that is, the composite with 100 wt. $\% \mathrm{RuO}_{2}$. $n \mathrm{H}_{2} \mathrm{O}$ loading, is just $c a .477 \mathrm{~F} \mathrm{~g}^{-1}$, which is much less than the $\mathrm{SC}_{\mathrm{Ru}}$ of the composite electrode with $24.8 \mathrm{wt} . \% \mathrm{RuO}_{2}$. $n \mathrm{H}_{2} \mathrm{O}$ NPs. It indicates that the electrochemical utilization of the $\mathrm{RuO}_{2} \cdot n \mathrm{H}_{2} \mathrm{O}$ species is enhanced greatly when $\mathrm{RuO}_{2}$. $n \mathrm{H}_{2} \mathrm{O}$ NPs are well dispersed upon the surface of the MCMB. It can be further verified by other composites with different $\mathrm{RuO}_{2} \cdot n \mathrm{H}_{2} \mathrm{O}$ loadings. As seen from Figure 4(c), the $\mathrm{RuO}_{2}$. $n \mathrm{H}_{2} \mathrm{O} / \mathrm{MCMB}$ composites with 12.5 wt. $\% \mathrm{RuO}_{2} \cdot n \mathrm{H}_{2} \mathrm{O}$ NPs can deliver a large $\mathrm{SC}_{\mathrm{Ru}}$ of $1115 \mathrm{Fg}^{-1}$. In addition, a $\mathrm{SC}_{\mathrm{Ru}}$ of $987 \mathrm{~F} \mathrm{~g}^{-1}$ still can be obtained even in the case of $52.4 \mathrm{wt} . \%$ $\mathrm{RuO}_{2} \cdot n \mathrm{H}_{2} \mathrm{O}$ NPs. It is worthy of noting that the $\mathrm{SC}_{\text {composite }}$ of the composite electrode with $52.1 \mathrm{wt} . \% \mathrm{RuO}_{2} \cdot n \mathrm{H}_{2} \mathrm{O}$ NPs is even larger than that of the bare $\mathrm{RuO}_{2} \cdot n \mathrm{H}_{2} \mathrm{O}$ NPs. Therefore, the existence of MCMB in the composites enhances the dispersion of $\mathrm{RuO}_{2} \cdot n \mathrm{H}_{2} \mathrm{O}$ NPs, which avoids the serious aggregation of $\mathrm{RuO}_{2} \cdot n \mathrm{H}_{2} \mathrm{O}$ NPs themselves and makes a great portion of ruthenium oxide NPs with large exposed surface contacted easily by the $\mathrm{H}^{+}$ions and electrons to participate in the electrochemical reaction for much efficient energy storage at high rates. Thus, a higher electrochemical utilization can be obtained for the composite electrodes.

To further determine the power performance of the electrodes, high-rate dischargeability (HRD) of the electrode was 


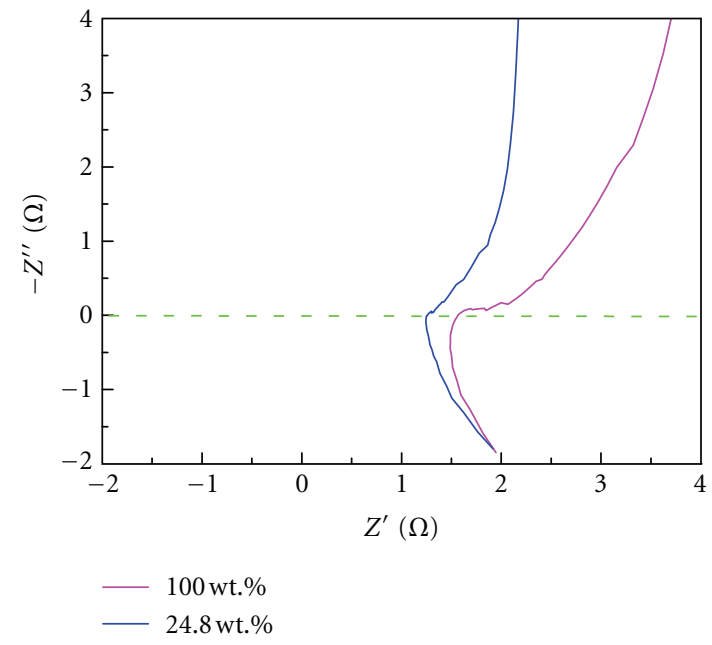

(a)

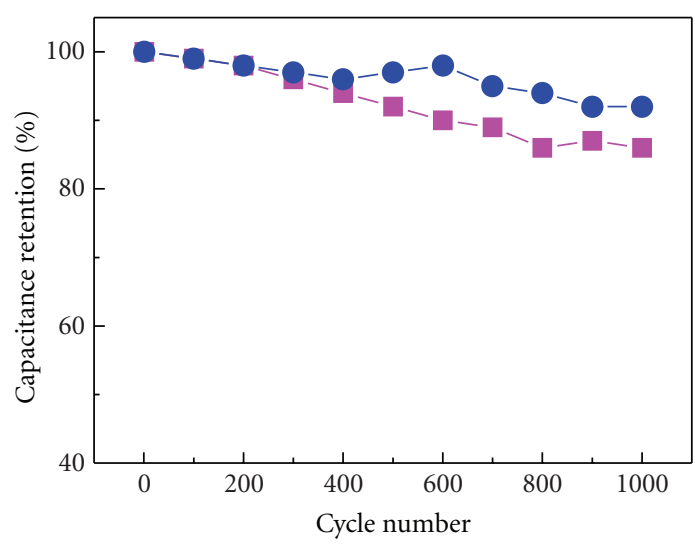

(b)

FIgURE 5: EIS plots (a) and cycling performance (b) of the $\mathrm{RuO}_{2} \cdot n \mathrm{H}_{2} \mathrm{O} / \mathrm{MCMB}$ composites with the $24.8 \mathrm{wt} . \%$ and $100 \% \mathrm{RuO} \cdot n \mathrm{H}_{2} \mathrm{O} \mathrm{NPs}$, respectively.

investigated in a current density range from 0.5 to $5 \mathrm{Ag}^{-1}$. Here, the HRD is defined as the ratio of $S_{\mathrm{Ru}}$ at a certain current density to that at $0.5 \mathrm{Ag}^{-1}$ and calculated according to

$$
\operatorname{HRD}(\%)=\frac{\mathrm{SC}_{\mathrm{Ru}, d}}{\mathrm{SC}_{\mathrm{Ru}, 0.5}} \times 100,
$$

where $\mathrm{SC}_{\mathrm{Ru}, d}$ and $\mathrm{SC}_{\mathrm{Ru}, 0.5}$ are the discharge $\mathrm{SC}_{\mathrm{Ru}}$ at a certain current density and $0.5 \mathrm{Ag}^{-1}$, respectively. Figure $4(\mathrm{~d})$ presents the HRD properties of the composite electrodes. Clearly, the HRD of the composites with $12.5 \mathrm{wt} . \%$ and 52.1 wt. $\% \mathrm{RuO}_{2} \cdot n \mathrm{H}_{2} \mathrm{O}$ loadings are $c a .73 \%$ and $79 \%$, respectively, much higher than that of $68 \%$ for the bare $\mathrm{RuO}_{2}$. $n \mathrm{H}_{2} \mathrm{O}$ NPs. It indicates that the composites can not only deliver large SCs but maintain them at high rates. Out of question, the existence of MCMB greatly enhances the power property of the electrodes, which is important for their practical application. The enhanced power property of the composite electrodes should be mainly related to their better electronic conductivity in contrast to that of the pure $\mathrm{RuO}_{2}$. $n \mathrm{H}_{2} \mathrm{O}$ NPs, which can be confirmed by the following EIS data shown in Figure 5(a).

Figure 5(a) shows the complex plane plots of the $\mathrm{RuO}_{2}$. $n \mathrm{H}_{2} \mathrm{O} / \mathrm{MCMB}$ composites with the $24.8 \mathrm{wt} . \%$ and $100 \%$ $\mathrm{RuO}_{2} \cdot n \mathrm{H}_{2} \mathrm{O}$ NPs, respectively. At very high frequencies, from the Nyquist plots, the intercept of the electrode with the real impedance $(Z)$ axis reports the sum of the internal resistance of the electroactive materials, electrolyte resistance, and the contact resistance at the interface between electroactive materials and current collector [21]. Here, due to the same making technique of the three-electrode cell for test, the electrolyte resistance and the contact resistance are identical for the two electrodes. Therefore, it can be considered that the different intercepts reflect the different conductive properties of the two composite themselves. As shown from the data in Figure 5(a), the $\mathrm{RuO}_{2} \cdot n \mathrm{H}_{2} \mathrm{O} / \mathrm{MCMB}$ composite with 24.8 wt. $\% \mathrm{RuO}_{2} \cdot n \mathrm{H}_{2} \mathrm{O}$ owns much better electronic conductivity ( $c a .1 .2 \mathrm{ohm}$ ) than the pure $\mathrm{RuO}_{2} \cdot n \mathrm{H}_{2} \mathrm{O}$ NPs (ca. $1.5 \mathrm{ohm}$ ). Commonly, the smaller the consisting particles are, the more significant interfacial resistance between adjacent particles becomes [22]. After well dispersing $\mathrm{RuO}_{2}$. $n \mathrm{H}_{2} \mathrm{O}$ NPs upon the surfaces of the MCMB with good electronic conductivity, the interfacial resistance can decrease to some extent.

For further understanding the electrochemical performances, the long-term cycle ability of the electrodes was also evaluated by repeating the charge/discharge test at a current density of $5 \mathrm{~A} \mathrm{~g}^{-1}$ for 1000 cycles. The SC as a function of the cycle number is presented in Figure 5(b). After 1000 continuous cycle tests, the $\mathrm{SC}$ degradation of the $\mathrm{RuO}_{2} \cdot n \mathrm{H}_{2} \mathrm{O}$ / MCMB composite with 24.8 wt. $\% \mathrm{RuO}_{2} \cdot n \mathrm{H}_{2} \mathrm{O}$ is $c a$. $8 \%$, much less than ca. $14 \%$ for the pure $\mathrm{RuO}_{2} \cdot n \mathrm{H}_{2} \mathrm{O}$ NPs, demonstrating that the $\mathrm{RuO}_{2} \cdot n \mathrm{H}_{2} \mathrm{O} / \mathrm{MCMB}$ composite can maintain better electrochemical stability than the single $\mathrm{RuO}_{2} \cdot n \mathrm{H}_{2} \mathrm{O}$ NPs phase.

\section{Conclusions}

In conclusion, an efficient hydrothermal strategy was proposed here to disperse $\mathrm{RuO}_{2} \cdot n \mathrm{H}_{2} \mathrm{O}$ NPs upon the surfaces of mesocarbon microbeads. Electrochemical capacitance of the $\mathrm{RuO}_{2} \cdot n \mathrm{H}_{2} \mathrm{O} / \mathrm{MCMB}$ composites were systematically investigated in $0.5 \mathrm{M} \mathrm{H}_{2} \mathrm{SO}_{4}$ aqueous solution. Electrochemical data indicated that the $\mathrm{RuO}_{2} \cdot n \mathrm{H}_{2} \mathrm{O} / \mathrm{MCMB}$ composites own higher electrochemical utilization, better power property, and better electrochemical stability than the pure $\mathrm{RuO}_{2}$. $n \mathrm{H}_{2} \mathrm{O}$ NPs. The good dispersion of $\mathrm{RuO}_{2} \cdot n \mathrm{H}_{2} \mathrm{O}$ NPs and the enhanced electronic conductivity make the $\mathrm{RuO}_{2} \cdot n \mathrm{H}_{2} \mathrm{O}$ NPs with large exposed surface contacted easily by $\mathrm{H}^{+}$ions and electrons to participate in more efficient Faradaic reactions for energy storage at high rates. 


\section{Acknowledgments}

This work was financially supported by Natural Science Foundation of Anhui Province (no. 10040606Q07), 2010 Young Teachers' Foundation of Anhui University of Technology (no. QZ201003), and Graduate Innovation Program of Anhui University of Technology (no. 2011009).

\section{References}

[1] B. E. Conway, “Transition from 'supercapacitor' to 'battery' behavior in electrochemical energy storage," Journal of the Electrochemical Society, vol. 138, no. 6, pp. 1539-1548, 1991.

[2] G. Schlichthorl and L. M. Peter, "Impedance and microwave reflectivity measurements on $\mathrm{n}-\mathrm{Si}$ in $1 \mathrm{M} \mathrm{LiCl} /$ methanol $\mathrm{I}$. Depletion and inversion layer formation," Journal of the Electrochemical Society, vol. 142, no. 8, pp. 2665-2669, 1995.

[3] C. C. Hu, K. H. Chang, and C. C. Wang, "Two-step hydrothermal synthesis of Ru-Sn oxide composites for electrochemical supercapacitors," Electrochimica Acta, vol. 52, no. 13, pp. 4411-4418, 2007.

[4] C. Z. Yuan, L. Chen, B. Gao, L. H. Su, and X. G. Zhang, "Synthesis and utilization of $\mathrm{RuO}_{2} \cdot \mathrm{xH}_{2} \mathrm{O}$ nanodots well dispersed on poly(sodium 4-styrene sulfonate) functionalized multiwalled carbon nanotubes for supercapacitors," Journal of Materials Chemistry, vol. 19, no. 2, pp. 246-252, 2009.

[5] C. C. Hu and W. C. Chen, "Effects of substrates on the capacitive performance of $\mathrm{RuO}_{\mathrm{x}} \cdot n \mathrm{H}_{2} \mathrm{O}$ and activated carbon$\mathrm{RuO}_{\mathrm{x}}$ electrodes for supercapacitors," Electrochimica Acta, vol. 19, no. 21, pp. 3469-3477, 2004.

[6] H. Kim and B. N. Popov, "Characterization of hydrous ruthenium oxide/carbon nanocomposite supercapacitors prepared by a colloidal method," Journal of Power Sources, vol. 104, no. 1, pp. 52-61, 2002.

[7] F. Pico, J. Ibañez, M. A. Lillo-Rodenas et al., "Understanding $\mathrm{RuO}_{2} \cdot \mathrm{xH}_{2} \mathrm{O} /$ carbon nanofibre composites as supercapacitor electrodes," Journal of Power Sources, vol. 176, no. 1, pp. 417425, 2008.

[8] B. J. Lee, S. R. Sivakkumar, J. M. Ko, J. H. Kim, S. M. Jo, and D. Y. Kim, "Carbon nanofibre/hydrous $\mathrm{RuO}_{2}$ nanocomposite electrodes for supercapacitors," Journal of Power Sources, vol. 168, no. 2, pp. 546-552, 2007.

[9] H. Honda and Y. Yamada, "Synthesis and stability of mesocarbon microbeads separated from the mesophase pitches," Journal of the Japan Petroleum Institute, vol. 16, p. 392, 1973.

[10] Y. Yamada, T. Imamura, H. Kakiyama, H. Honda, S. Oi, and K. Fukuda, "Characteristics of meso-carbon microbeads separated from pitch," Carbon, vol. 12, no. 3, pp. 307-319, 1974.

[11] Y. G. Wang, Y. Korai, and I. Mochida, "Carbon disc of high density and strength prepared from synthetic pitch-derived mesocarbon microbeads," Carbon, vol. 37, no. 7, pp. 10491057, 1999.

[12] H. Honda, "Mesophase putch and meso-carbon microbeads," Molecular Crystals and Liquid Crystals, vol. 94, no. 1-2, pp. 97108, 1983.

[13] T. Kasuh, D. A. Scott, and M. Mori, "Active carbon and processes for synthesis of same," in Proceedings of an International Conference on Carbon, Newcastle, Extended Abstracts, p. 146, September 1988.

[14] C. Y. Wang, H. Jiang, P. Li, and J. M. Zheng, "Structure of mesocarbon microbeads formed with original QI as seed crystal," New Carbon Materials, vol. 15, p. 9, 2000.
[15] R. Alcantara, F. J. Fernanfez Madrigal, P. Lavela et al., "Characterization of mesocarbon microbeads (MCMB) as active electrode material in lithium and sodium cells," Carbon, vol. 38, p. 1031, 2000.

[16] J. Yamaura, Y. Ozaki, A. Morita, and A. Ohta, "High voltage, rechargeable lithium batteries using newly-developed carbon for negative electrode material," Journal of Power Sources, vol. 43, no. 1, pp. 233-239, 1993.

[17] A. Mabuchi, K. ToKumitsu, H. fujimoto, and T. Kasuh, "Charge-Discharge Characteristics of the Mesocarbon Miocrobeads Heat-Treated at Different Temperatures," Journal of the Electrochemical Society, vol. 142, no. 9, pp. 1041-1046, 1995.

[18] K. Tokumitsu, H. Fujimoto, A. Mabuchi, and T. Kasuh, "High capacity carbon anode for Li-ion battery a theoretical explanation," Carbon, vol. 37, no. 10, pp. 1599-1605, 1999.

[19] G. Q. Zhang and X. G. Zhang, " $\mathrm{MnO}_{2} / \mathrm{MCMB}$ electrocatalyst for all solid-state alkaline zinc-air cells," Electrochimica Acta, vol. 49, no. 6, pp. 873-877, 2004.

[20] C. Yuan, B. Gao, L. Su, and X. Zhang, "NiO loaded on hydrothermally treated mesocarbon microbeads (h-MCMB) and their supercapacitive behaviors," Solid State Ionics, vol. 178, no. 35-36, pp. 1859-1866, 2008.

[21] C. Yuan, X. Zhang, Q. Wu, and B. Gao, "Effect of temperature on the hybrid supercapacitor based on $\mathrm{NiO}$ and activated carbon with alkaline polymer gel electrolyte," Solid State Ionics, vol. 177, no. 13-14, pp. 1237-1242, 2006.

[22] C. C. Hu, W. C. Chen, and K. H. Chang, "How to achieve maximum utilization of hydrous ruthenium oxide for supercapacitors," Journal of the Electrochemical Society, vol. 151, no. 2, pp. A281-A290, 2004. 


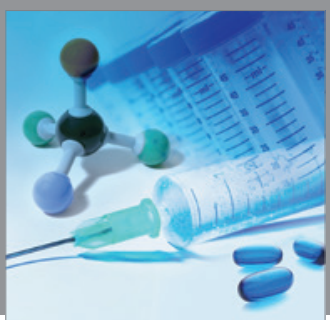

International Journal of

Medicinal Chemistry

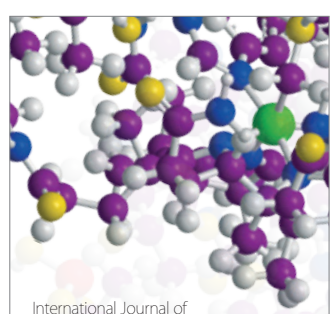

Carbohydrate Chemistry

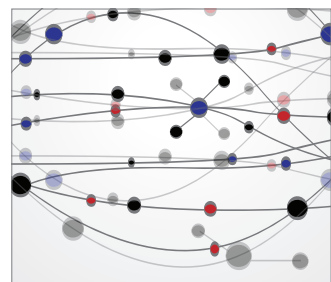

The Scientific World Journal
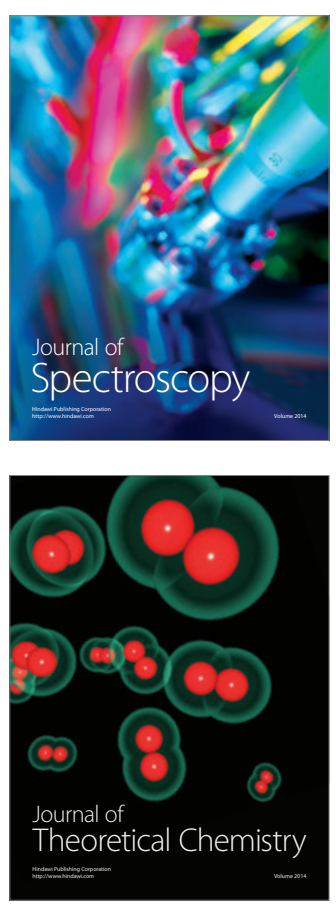
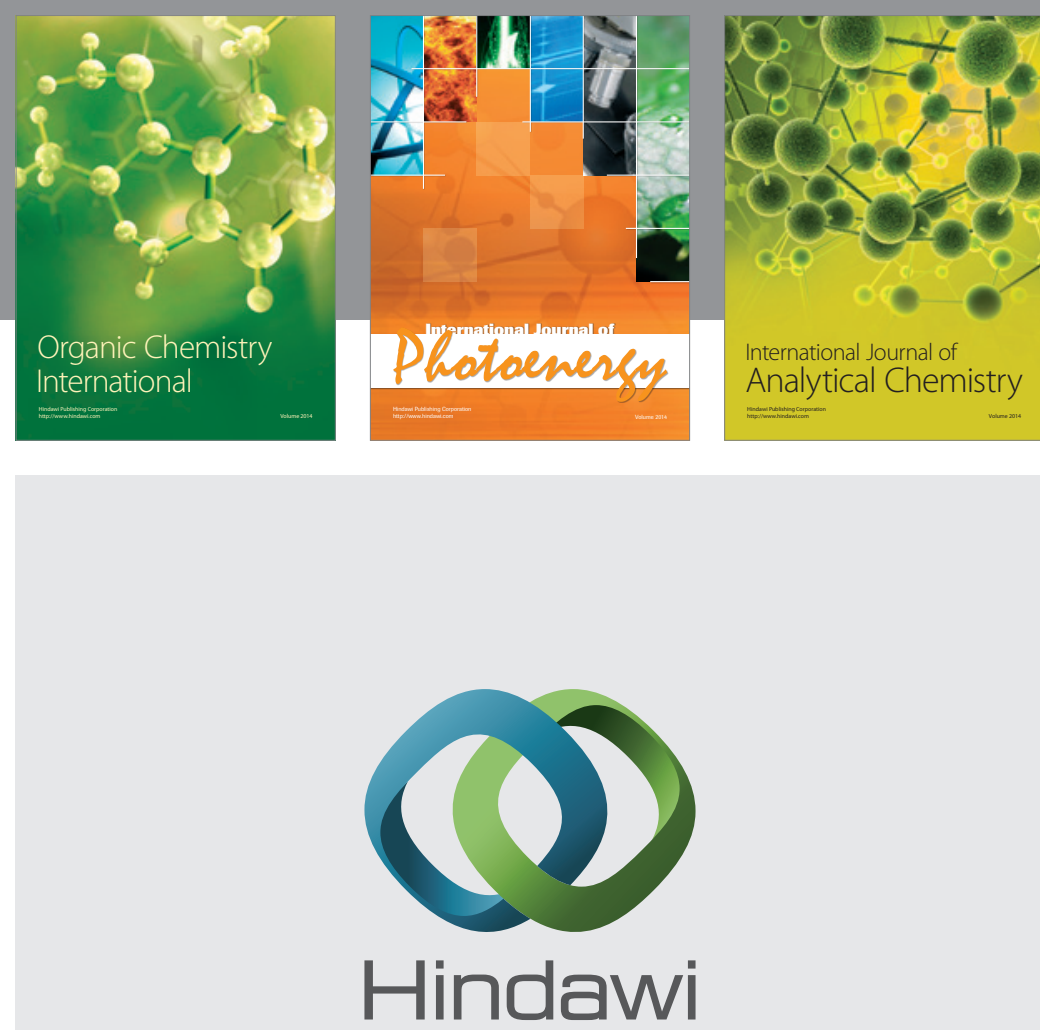

Submit your manuscripts at

http://www.hindawi.com
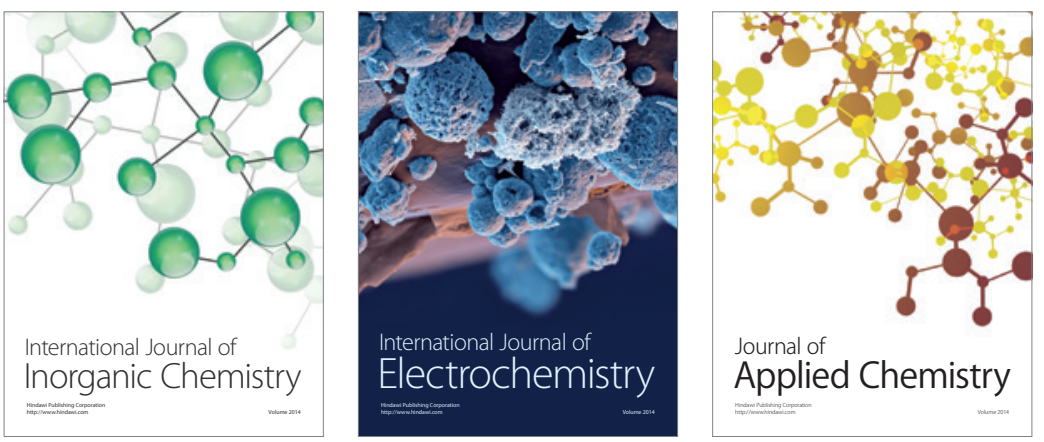

Journal of

Applied Chemistry
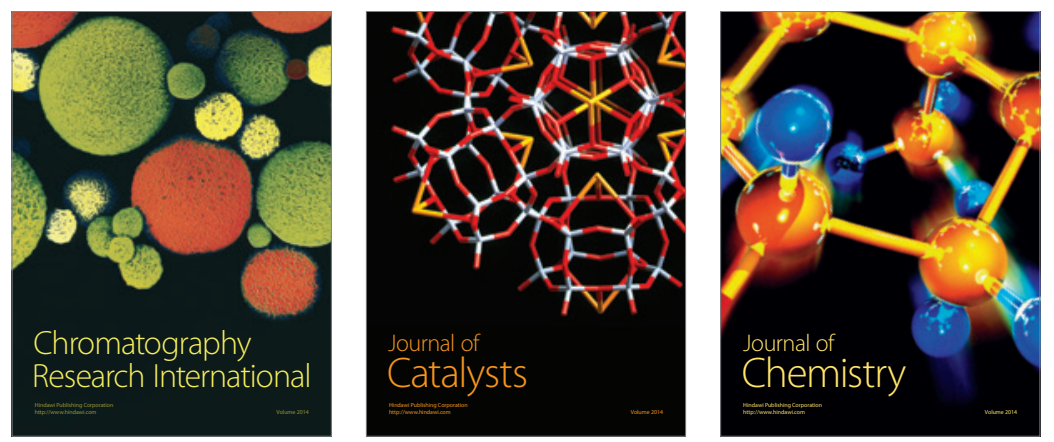
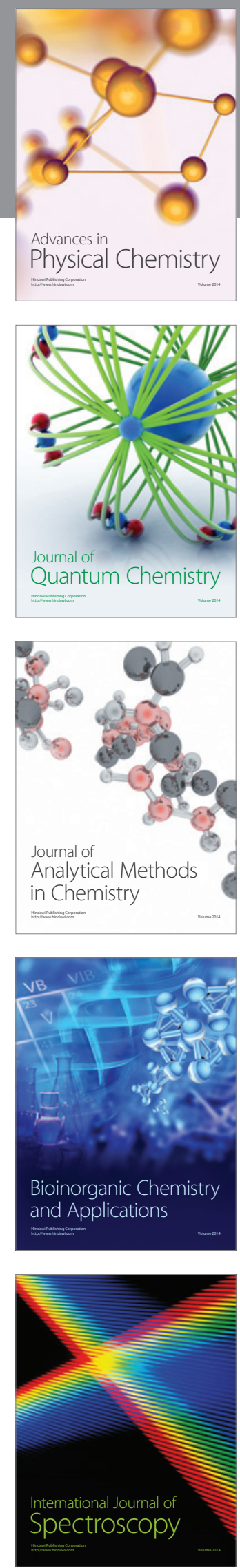